\title{
Is Engineering Ethics Important for Aerospace Engineers?
}

\author{
Sakineh Haghighattalab ${ }^{1, a}$, An Chen ${ }^{1, b}$ and Mohammadreza Saghamanesh ${ }^{2}$ \\ ${ }^{1}$ Institutes of Science and Development, Chinese Academy of Sciences, Beijing 100190, China \\ ${ }^{2}$ School of Aerospace Engineering, Tsinghua University, Beijing, 100084, China
}

\begin{abstract}
Engineering as a profession has a direct effect on society and the environment. Engineering ethics is a part of the essence of engineering. One of the important branches of engineering profession is aerospace engineering. Furthermore, aerospace industry achievements play an undeniable role in our lives. Research and development in the aerospace domain have contributed to the progress of some new technologies in the last decades. The purpose of this study is to emphasize the importance of engineering ethics as an essential part of aerospace engineering. Engineering ethics examines professional responsibilities and ethical decision making of engineers. Moreover, codes of ethics help the engineers to apply ethical principles in critical conditions. The poor ethical decision-making of engineers leads to engineering failures which jeopardized human life and the environment. This paper by examining two case studies related to the field of aerospace engineering (Challenger and Columbia disasters) describes the role of the negligence of engineering ethics on the occurrence of engineering disasters.
\end{abstract}

\section{Introduction}

Science and ethics are inseparably connected. Ethics is a necessary basis for science. Some ethical issues have a fundamental impact on all scientific activities [1]. Carl Mitcham notes "when science takes the world into its laboratory, engineering takes the world for a laboratory" [2]. In addition, the role of the engineering profession in creating advanced technologies has caused that the engineers pay more attention to the consequences of their designs and decisions. [3].

Engineering plays a key role in society and the environment. Moreover, engineering ethics is considered as a component of the essence of engineering. Engineers often face conditions in which they do not have enough data and cannot be completely certain that their design will never damage anyone or cause hurtful changes to society [4]. Hence, the design of engineers should be based on the highest standards of integrity and honesty. According to NSPE code of ethics for engineers "the services provided by engineers require honesty, impartiality, fairness, and equity, and must be dedicated to the protection of the public health, safety, and welfare. Engineers must perform under a standard of professional behavior that requires adherence to the highest principles of ethical conduct"[5]. The evidence within the engineering ethics literature indicates that disregard for ethics by engineers have been lead to many engineering disasters $[4,6,7]$. Some well-known disaster cases

\footnotetext{
a haghighattalab61@gmail.com

${ }^{\mathrm{b}}$ Corresponding author: anchen@casipm.ac.cn
} 
which are resulting immorality in engineering are Challenger Disaster (1986), Bhopal Disaster (1984), Chernobyl nuclear disaster (1986), Columbia Disaster (2003), Hydrolevel Corporation (1971) [6, 8].

One of the important branches of engineering is aerospace engineering. Aerospace achievements have an undeniable role in our lives. Furthermore, the progress in many industries such as the transportation field, health domain, safety, and autonomy has seen significant advances in the last decades due to the aerospace research and development [9].

The goal of this study is to emphasize the importance of engineering ethics as an essential part of the engineering activities especially in the field of aerospace engineering. In this paper, by exploring two space shuttle case studies (Challenger and Columbia), we will illustrate the role of disregarding to ethics on the occurrence of disasters. The studies in Challenger accident have revealed a violation of engineering ethics by managers and engineers as a significant cause of the disaster $[10,11]$. Seventeen years later, the Columbia disaster repeated with ethical reasons similar to the Challenger. For more clarification, the descriptions of ethics and engineering ethics are presented in next sections.

\section{Ethics}

Ethics is defined as "the study of the characteristics of morals" [4]. Ethics is a communication behavior based on respecting the rights of others. Ethics is being accountable for individuals' rights [12]. Ethics are divided into three categories in an initial division [6] (see Fig. 1).

Common ethics: the series of common moral ideals. In fact, lie, break promises, cheat, steal, harming others physically are some concepts that we think about them when we imagine ethics.

Personal ethics: the series of ethical beliefs that are usually obtained from religious, education or family.

Professional ethics: "the set of standards adopted by professionals insofar as they view themselves acting as professionals." Every profession such as architecture, law, pharmacy and, engineering has its professional ethics [6].

Figure 1. Categorization of Ethics [6]

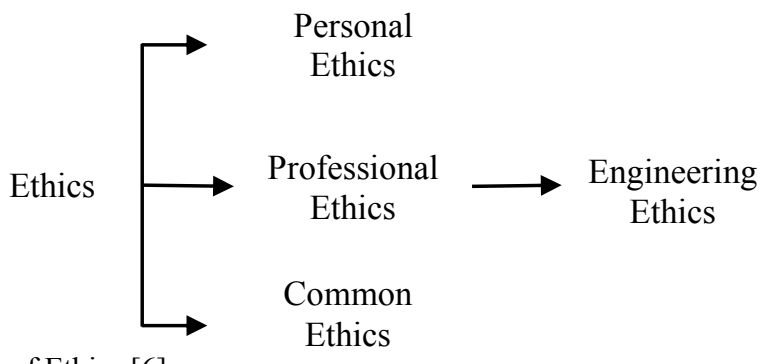

\section{Engineering ethics}

Engineering faces many ethical issues and challenges in its development process and needs to resolve its dilemmas with the help of ethical guidance related to the engineering profession [13, 14]. Engineering ethics "is the rules and standards governing the conduct of engineers in their role as Professionals"[4]. Engineering ethics has developed in the last three decades with two goals: the prevention of engineers' unethical behavior, and the prevention of technology threats to the public health and safety $[15,16]$. Professional engineering ethics can be considered in two parts: 1) preventive ethics that focuses on preventing professional misbehavior and engineering disaster 2) aspirational ethics that inclined to make a better life via technology [6].

Many engineers are salaried employees of corporations or organizations. Since companies usually try to gain more profit, some managers may pay little attention to the safety in their decisions. Engineering ethics helps to solve the conflicts between management cost-benefit calculations and the engineer obligations to public safety [11]. Often, the correct responses to ethical dilemmas in 
engineering profession are difficult and cannot be solved by engineers and managers. Engineering ethical codes help engineers to solve such ethical dilemmas.

Professional codes of ethics are one signs of the modern societies. Lynch and Kline believe that the perception of the significance of ethical codes is main elements of engineering ethics instruction [11]. For example, one of the most famous ethical codes of the engineering is the IEEE (Institute of Electrical and Electronics Engineers) Code of Ethics. Some of the IEEE codes are as follows: "1) to hold paramount the safety, health, and welfare of the public, to strive to comply with ethical design and sustainable development practices, and to disclose promptly factors that might endanger the public or the environment; 2) to avoid real or perceived conflicts of interest whenever possible, and to disclose them to affected parties when they do exist; 3) to be honest and realistic in stating claims or estimates based on available data; 4) to reject bribery in all its forms" [17]. Engineers have to pursue their profession's code of ethics and also know that their professional responsibilities are beyond these codes [18].

A significant point of engineering ethics literature is the study of disaster cases [4, 15, 19]. Case studies have some advantages such as permitting engineers to know the essence of a problem and learning to choose the best decision in the prevention of disasters [20]. The Challenger and Columbia disasters as two engineering ethics cases are presented in the next sections.

\section{The Challenger disaster}

The Challenger disaster because of its complexity is analyzed by many ethicists as well as managers and engineers to understand professional misconduct (see Fig. 2). To know about the details of the Challenger disaster, please refer to [21-22].

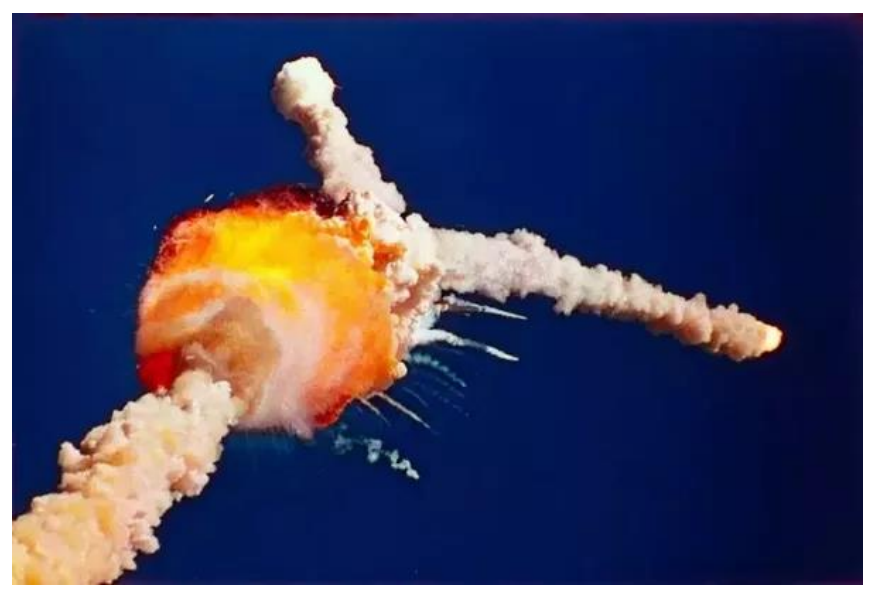

Figure 2. The Challenger disaster

"On January 28, 1986, the space shuttle Challenger exploded 73 seconds into its flight, killing the seven astronauts aboard" [21]. The technical cause of the incident was due to "a failure of the o-rings, the seals in the connecting joint between two segments of the rocket booster, to seal one of the boosters thereby creating the environment for the fuel explosion that resulted" [22].

Three groups of human factors played principal roles in the occurrence of the incident: Thiokol engineers and managers who were directly responsible for the launch and also NASA officials as signatories the launch [22-23].

Before the Challenger launch, a team of NASA held a meeting with engineers of Morton Thiokol to talk about the safety of launching. Morton Thiokol engineers pointed to problems with O-rings in 7 of the past 24 shuttle launches and warned a connection between low temperatures and O-ring problems. They stated that the launch should be stopped, but the warning of engineers was not accepted by NASA officials. The four senior managers ignored the advice of engineers and voted for 
the launch. NASA quickly accepted the managers' opinion that led to a human and technical failure [21].

NASA accepted more risks due to pressure to keep the congressional budget. NASA management contravened rules because of the shuttle program's continued economic viability. The unfortunate issue was that the NASA managers who recommended the launch did not inform the astronauts of the risk. They easily violated the human and ethical rights of astronauts.

In fact, the Challenger accident was the result of the difference in priorities between the engineers and management at Thiokol and NASA, some conflicts in organizational culture and, the failure of managers and engineers in the application of individual ethical responsibility [22]. In addition, selfdeception had been penetrated in the NASA space program. The case demonstrates how the selfdeception can affect the engineers and limit them to predict risk correctly [6]. Boisjoly et al. revealed that the governing organization of the Challenger undermined the individual decision maker's responsibilities and became a tool for avoiding real and efficient accountability in the whole management system [21]. In summary, disregarding ethical responsibility is revealed with reflecting on some cases: decision-making processes were not in accordance with the standards of NASA or communication specialists; the design and practice process was flawed; the final decision to launch was a huge risk regardless of the importance and respect for the lives of astronauts; the decision makers sacrificed the moral concepts in their actions to attain their purposes [24].

\section{The Columbia disaster}

Seventeen years later, the Columbia disaster as another significant aerospace accident occurred. Like Challenger, the non-technical causes were insufficient attention to ethical principles, especially at managerial levels (see Fig. 3). On February 1, 2003, NASA's space shuttle Columbia during returned to the earth, broke and all seven astronauts were killed. The Columbia Accident Investigation Board stated that technical and organizational causes had a role in the Columbia disaster [25].

The technical cause was "damage to Columbia's left wing by a 1.7 pound piece of insulating foam that detached from the left "bipod ramp" that connects the External Tank1 to the orbiter, and struck the orbiter's left wing 81.9 seconds after launch. The foam strike created a hole in a Reinforced Carbon-Carbon (RCC) panel on the leading edge of the wing, allowing superheated air (perhaps exceeding $5,000 \mathrm{o} F$ ) to enter the wing during reentry. The extreme heat caused the wing to fail structurally, creating aerodynamic forces that led to the disintegration of the orbiter"[25-26].

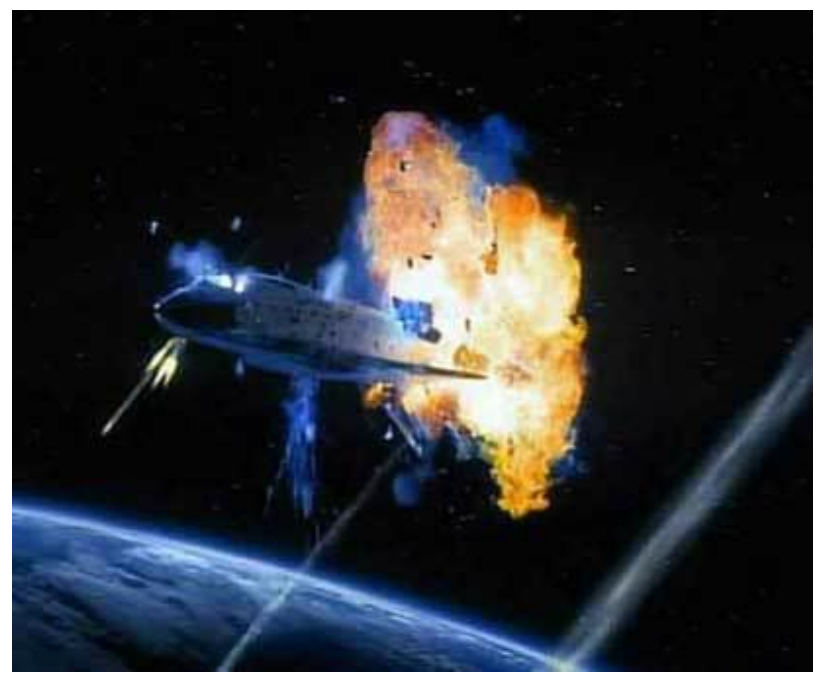

Figure 3. The Columbia disaster 
The organizational causes were “...rooted in the Space Shuttle Program's history and culture, including the original compromises that were required to gain approval for the Shuttle, subsequent years of resource constraints, fluctuating priorities, schedule pressures, mischaracterization of the Shuttle as operational rather than developmental, and lack of an agreed national vision for human space flight. Cultural traits and organizational practices detrimental to safety were allowed to develop, including: reliance on past success as a substitute for sound engineering practices..., organizational barriers that prevented effective communication of critical safety information and stifled professional differences of opinion; lack of integrated management across program elements; and the evolution of an informal chain of command and decision-making processes that operated outside the organization's rules" [25-26]. Unfortunately, in the Columbia program, without enough budget and schedule, quality was seriously compromised, so that safety also faced with baleful consequences.

To summarize, the Challenger and Columbia have some resemblances in the unethical decision making of senior-level managers that lead to the similar tragedies. In both accidents, the managers did not pay attention to the experience of engineers and experts' consultations due to organizational considerations [27]. In both the Challenger and Columbia disasters, budget and schedule were limited. The organizational and bureaucratic structure was also a common issue between both incidents. It caused a barrier to the receiving of important data. Furthermore, self-censorship as a significant factor in the organization resulted in having incorrect information for decision-making [28]. Finally, it must be said that with regard to ethical issues that led to these two cases, applying engineering ethics to decision making within crucial conditions can prevent the similar engineering disasters in the future.

Since the 1950s, aerospace engineering and technology have been considered as a national issue in many countries because it has crucial consequences for defense and economics. For this reason, many governments and private companies are working more than ever in aerospace investigations. Hence, engineering ethics should be more considered in the aerospace field due to the serious role of the aerospace technology on many current technologies. As mentioned above, ethical codes play an important role in engineers' decision making. Therefore, this paper suggests that further investigation should be done to design codes of ethics for the various specialties within aerospace engineering.

\section{Conclusion}

The aerospace as a significant and effective branch of the engineering profession has contributed to the development of many new technologies. In addition, the aerospace engineering has a serious role in the defense and economics for many countries in the last decades. Moreover, the case studies in this paper demonstrated that ethical weaknesses such as mismanagement and negligence of safety issues play a crucial role in the occurrence of engineering disasters. Therefore, the attention to engineering ethics should be bolstered in the aerospace engineering. At last, this study suggested that future research is needed to design ethical codes as a framework for ethical decision making of engineers and managers in the field of aerospace engineering.

\section{Acknowledgments}

This work has been supported by CAS-TWAS President's Fellowship for International Ph.D. Student.

\section{References}

1. H. Zwart, Frontis, 67-80 (2005)

2. C. Mitcham, Thinking ethics in technology: Hennebach lectures and papers, 138 (1997)

3. J. M. Basart, M. Serra, Sci. Eng. Ethics. 19 179-187 (2013)

4. C. B. Fleddermann, Engineering ethics, 4 (1999)

5. NSPE Code of Ethics (1993) 
6. C. E. Harris Jr, M. S. Pritchard, M. J. Rabins, R. James, E. Englehardt, Engineering ethics: Concepts and cases (2013)

7. D. P. Michelfelder, N. McCarthy, D. E. Goldberg, Philosophy and engineering: Reflections on practice, principles and process, 15 (2014)

8. J. Ladd, in Ethical issues in the use of computers, 8-13 (1985)

9. W. Staszewski, C. Boller, G. R. Tomlinson, Health monitoring of aerospace structures: smart sensor technologies and signal processing (2004)

10. M. W. Martin, R. Schinzinger, Ethics in engineering, 23 (2005)

11. W. T. Lynch, R. Kline, Sci. Technol. Human. Values. 25 195-225 (2000)

12. A. Gharamaleki, Introduction to professional Ethics (2009)

13. D. Nieusma, D. Riley, Eng. Stud. 2 29-59 (2010)

14. J. Beever, A. O. Brightman, Sci. Eng. Ethics. 22 275-291 (2016)

15. C. E. Harris Jr, Sci. Eng. Ethics. 14 153-164 (2008)

16. R. D. Hollander, In Engineering ethics for a globalized world, 55-67 (2015)

17. IEEE Code of Ethics (2006)

18. M. Davis, Philos. Public. Aff. 150-167 (1991)

19. M. Davis, Thinking like an engineer: Studies in the ethics of a profession (1998)

20. C. J. Abaté, Sci. Eng. Ethics. 17 583-596 (2011)

21. R. P. Boisjoly, E. F. Curtis, E. Mellican, J. Bus. Ethics. 8 217-230 (1989)

22. P. H. Werhane, J. Bus. Ethics. 10 605-616 (1991)

23. B. S. Romzek, M. J. Dubnick, Public. Adm. Rev. 227-238 (1987)

24. R. C. Kramer, J. A. Jaksa, Eric. (1987)

25. C. A. I. Board, 1 (2003)

26. M. S. Smith, NASA's Space Shuttle Columbia: Synopsis of the Report of the Columbia Accident Investigation Board (2003)

27. T. M. Garrett, Am. Rev. Public Adm. 34 389-402 (2004)

28. R. Dimitroff, L. Schmidt, T. Bond, PMJ. 36 28-38 (2005) 